\title{
Agôn
}

6 | 2013

La Reprise

\section{3 // 2013 : Le Sacre du Printemps}

Sacre Colloquium, Charleroi/Danses, Kaaitheater

Marion Rhéty

\section{(2) OpenEdition}

Journals

Édition électronique

URL : https://journals.openedition.org/agon/2928

DOI : $10.4000 /$ agon.2928

ISSN : 1961-8581

Éditeur

Association Agôn

Référence électronique

Marion Rhéty, « 1913 // 2013 : Le Sacre du Printemps », Agôn [En ligne], 6 | 2013, mis en ligne le 12 mars 2014, consulté le 28 juin 2022. URL : http://journals.openedition.org/agon/2928 ; DOI : https://doi.org/ 10.4000/agon.2928

Ce document a été généré automatiquement le 29 septembre 2020.

Association Agôn et les auteurs des articles 


\section{3 // 2013 : Le Sacre du Printemps}

Sacre Colloquium, Charleroi/Danses, Kaaitheater

\section{Marion Rhéty}

\section{RÉFÉRENCE}

Sacré Sacre du Printemps, Laurent Chétouane, pièce vue le 20 novembre 2013 au Kaaitheater.

Nous remercions les intervenants et organisateurs de ce colloque, Charleroi/Danses et le Kaaitheater, qui s'est tenu le 21 novembre à la Raffinerie Charleroi/Danses à Bruxelles.

\section{Présentation du colloque}

1 La renommée du Sacre du Printemps s'est forgée à travers le scandale qui l'a accueilli, scandale « programmé » Diaghilev qui choisit pour la première la date anniversaire de la création du Faune, déjà reçu de façon très mouvementée. L'œuvre étant fondatrice de la modernité en danse, plus de deux cents chorégraphes s'y sont depuis confrontés, les uns s'inscrivant dans une archéologie patiente de ces fragments de corps disparus, les autres parcourant librement ce pan de l'histoire de la scène.

2 À l'occasion du centenaire de la création du Sacre du Printemps de Nijinski, Stravinski et Rœrich, Charleroi/Danses et le Kaaitheater se sont associés pour programmer quatre versions du Sacre et organiser un colloque sur cette pièce majeure du $20^{\mathrm{e}}$ siècle. Orientant les questionnements sur la notion de sacrifice, les différents intervenants cartographient leurs itinéraires au sein de cette œuvre, en définissent les distances, les frontières, les chemins de traverse. L'œuvre est devenue monument que les fantômes hantent toujours. Car si les versions se démultiplient, c'est toujours la première que l'on retient.

3 Dans le cadre de ce dossier sur la reprise dans les arts de la scène, nous choisissons de rendre compte de certaines de ces interventions ${ }^{1}$, tantôt par l'écrit, tantôt par l'archive 
sonore. Nous restituons donc les interventions de Christophe Wavelet pour sa mise en perspective des enjeux du Sacre et de son insistance dans l'histoire ; de Dominique Brun pour sa recherche entamée depuis plus de vingt ans sur la reconstitution, la recréation, la reprise d'une œuvre dont il ne reste que peu de traces tangibles; de Laurent Chétouane pour sa prise de parole sur sa pièce Sacré Sacre du Printemps, qui vient compléter une critique de cette pièce; de Cristel Stalpaert, qui propose une relecture diachronique des différentes versions du Sacre par la question de la vieillesse.

- Christophe Wavelet - Perspectives sur le Sacre

- Dominique Brun - L'archive à l'épreuve de la scène

- Laurent Chétouane - Qu'y a-t-il après le sacrifice?

\section{Christophe Wavelet - Perspectives sur le Sacre}

Critique et chercheur, Christophe Wavelet a notamment fait partie du Quatuor Albrecht Knust, aux côtés de Dominique Brun, Anne Collod et Simon Hecquet, quatuor fondé en 1993 pour questionner l'héritage de la modernité en danse, en s'appuyant sur le système de notation Laban.

Ce média ne peut être affiché ici. Veuillez vous reporter à l'édition en ligne http:// journals.openedition.org/agon/2928

\section{Dominique Brun - L'archive à l'épreuve de la scène}

Danseuse et chorégraphe française, membre du Quatuor Albrecht Knust, elle travaille depuis plus de vingt ans sur la reconstitution, la recréation, la reprise d'une œuvre déjà dansée, particulièrement sur l'Après-midi d'un Faune et sur le Sacre du Printemps.

Ce média ne peut être affiché ici. Veuillez vous reporter à l'édition en ligne http:// journals.openedition.org/agon/2928

\section{Laurent Chétouane - Qu'y a-t-il après le sacrifice ?}

Metteur en scène et chorégraphe français travaillant en Allemagne, il a créé Sacré Sacre du Printemps. Il s'entretient ici avec Christophe Wavelet.

Ce média ne peut être affiché ici. Veuillez vous reporter à l'édition en ligne http://

\section{Laurent Chétouane, Qu'y a-t-il après le Sacre ? Critique de la pièce par Marion Rhéty}

10 Parler du Sacre de Laurent Chétouane, c'est d'abord parler des corps qu'il convoque sur scène. Et de ces corps, on retiendra le visage. Si la danse contemporaine s'est construite par la déhiérarchisation des parties du corps, notamment des parties expressives, 
porteuses de signe et de sens, Laurent Chétouane réhabilite le visage comme lieu de l'adresse. Quelques traces d'un maquillage primitif façonnent ces visages dans leurs reliefs, traces rouges sur les joues, rectangle noire sur une bouche, un front marqué de brun, comme autant de signes qui distinguent et rassemblent du même élan. Ainsi se dessinent pour chacun des sept interprètes les prémisses de la formulation, de l'expression, ce déport vers l'autre. C'est dans ce sens-là que l'animalité des corps que cherchait à composer Nijinski est à saisir. Ouvrir la bouche. Ce geste qui est à la fois trouer, accueillir, faire affleurer l'intérieur et aller vers. Les mâchoires s'entrouvrent et se referment, sur le qui-vive, feulent. Les corps ne sont pas violents, mais potentiellement violents, et tout se situe là, dans cette possibilité, cette puissance d'agir. Avec douceur aussi. Ces corps expressifs sans expressionnisme, quotidiens sans réalisme, dansent l'amplitude d'une plasticité au monde.

11 Il en va du traitement des visages comme du reste de la pièce : le rapport à l'espace, à la musique, au temps, au poids, au groupe, à la composition, chaque paramètre aux fondements de la danse contemporaine est ainsi remis en jeu. Réinventant l'espace, le plateau est utilisé dans tous ses points cardinaux, jouant sur son ouverture et sa fermeture par les déplacements des corps, jusqu'à la face, à l'adresse claire en bord de plateau, jusqu'au hors-champ ou presque, par des percées, qui, loin d'être des fuites, font exister cet espace nouveau, habité par l'un des danseurs. Entre deux murs blancs latéraux comme seul décor, le groupe transforme sans cesse la distance entre lui et les spectateurs. Quant à la musique, composée par Léo Schmidthals, tissée sur la partition originale de Stravinski, Laurent Chétouane dit que contrairement à la pièce de Nijinski, ce n'est pas elle qui guide la danse vers le sacrifice de l'élue : si les corps sont des rocs, et que la musique est l'eau au-dessus, alors le regard du spectateur agit comme la lumière qui se diffracte. Les danseurs écoutent la musique, ils ne la portent pas, ni ne la servent.

Loin de renoncer à la danse, dans ce qu'elle peut avoir de technique aussi, dans ce travail de précision des corps, ils jouent d'un vocabulaire académique identifiable, avec une liberté rare, affranchie de sa normativité, mieux, la dépassant pour inventer langage nouveau. C'est sans doute un des grands intérêts de cette pièce, car c'est par ces questionnements sur le langage contemporain que le chorégraphe se saisit de cette partition magistrale. Si le Sacre du printemps créé en 1913 par Nijinsji, Stravinski et Rœrich traverse le temps et que les chorégraphes ne cessent de se l'approprier, de tenter de le retrouver, de le détourner... c'est notamment par le succès venu de son scandale. Par les ruptures qu'elle induisit d'avec la gestuelle et l'éthos classique, la pièce est considérée comme fondatrice de la modernité en danse, pierre angulaire d'une histoire de la danse écrite par ses scandales. Laurent Chétouane entreprend cette révolution aujourd'hui. C'est à cet endroit-là qu'il fait reprise, réitérant le positionnement de Nijinski face à ses pères. Refusant toute métonymie par la radicalité de son écriture, préférant un rapport diachronique à l'œuvre, l'original n'est ni magnifié, ni répudié. Dans ce Sacré Sacre du Printemps, il sacrifie le Sacre mais ne l'annule pas.

13 Et après ? Loin d'une vision nihiliste ou mélancolique, il pose la question de l'après : il n'y a pas de sacrifice de l'élue sur scène, il a déjà eu lieu. Dès lors, il s'agit de penser comment le groupe peut s'organiser après l'exclusion de l'un de ses membres. Comment la communauté trouve-t-elle son régime d'existence ? À cette lecture du sacrifice de l'œuvre s'ajoute donc celle non moins centrale de l'autre, de l'étranger, par 
là, de la relation entre soi et l'autre. Cet autre, Laurent Chétouane affirme qu'il est à chercher en soi. La relation se matérialise dans la métamorphose des espaces entre les danseurs. Les mouvements sont à la fois généreux par leur présence et leur densité, et contenus : au bord de la falaise, cela pourrait basculer à tout moment. Les membres du groupe émergent les uns après les autres, comme exclus par un léger débord, de ce qui n'a pas su se contenir quand tout était pourtant si important, par le surgissement d'une dépense. Il sera rattrapé par le groupe, pour une autre dépense. Selon ses propres mots, Laurent Chétouane traite de notre «incapacité à laisser l'étranger exister dans son altérité ", déplaçant la question du pouvoir adressée à un groupe à l'intérieur des corps de chacun. Un modèle ne prend pas la place de l'autre, mais l'attention reste vive pour inventer, sans la figer, cette communauté.

\section{NOTES}

1. Une partie des questions était tournée vers la musique, avec les interventions de Gaétan Bulourde, brillante par son humour et son iconoclasme, de Juan Pablo Carreno, compositeur pour Sacre \#197 de Dominique Brun, et du musicologue Francis Maes. S'éloignant de l'objet de notre dossier, nous n'en rendons pas compte ici. De même pour l'invitation faite à Cristina Rizzo et à Emmanuelle Huynh.

\section{INDEX}

Mots-clés : Sacre du printemps (Le), Nijinski (Vaslav), reprise 